\title{
Fibrous dysplasia of the orbit
}

\author{
K Bibby, R McFadzean
}

\begin{abstract}
Twelve patients with fibrous dysplasia of the orbit are reviewed and the ophthalmic findings described. Three case histories are presented in detail. Six patients were managed conservatively; four have shown radiological progression of the disease. Six patients underwent surgery. A conservative procedure, comprising debulking dysplastic bone, was carried out in four - all required further surgery including radical excision in two patients. Two subjects had primary radical operations. No recurrence was encountered in the four patients who had undergone radical surgery. It would appear that fibrous dysplasia is not a disease confined to adolescence but may continue into adulthood, and even middle age. Patients may never require surgery, but require follow up for late progression. If surgical intervention is deemed necessary, an attempt should be made to excise all dysplastic bone, since progression of the disease after conservative surgery is relatively common.

(Brf Ophthalmol 1994; 78: 266-270)
\end{abstract}

Fibrous dysplasia is a benign, slowly progressive disorder of bone, where normal cancellous bone is replaced by fibrous tissue and immature woven bone. It presents in childhood or early adolescence, ${ }^{1}$ typically arresting at puberty. ${ }^{2}$

The lesions were first described by von Recklinghausen in $1891,{ }^{3}$ but it was Lichtenstein in 1938 who recognised the condition as a distinct entity and suggested the name 'fibrous dysplasia'. ${ }^{4}$ The condition occurs in the monostotic form, where only one or contiguous bones are involved, or polyostotic form where several distinct areas of the skeleton are affected. Fibrous dysplasia can occur in conjunction with skin pigmentation and endocrine disorders (Albright's syndrome). ${ }^{5}$ The disease has been prevalent for a long time; it was described in the skeleton of a seventh century Anglo Saxon, ${ }^{6}$ and in a skull found in Tennessee, dated $\mathrm{AD} 1480$ (plus or minus 130 years, carbon dating). ${ }^{7}$

More than 1500 cases were reported in the literature up until $1971,{ }^{8}$ but estimates of the

Accepted for publication 23 September 1993

Table 1 Fibrous dysplasia-bones affected

\begin{tabular}{llllllllllllll}
\hline & \multicolumn{2}{l}{ Patient } & & & & & & & & & & & \\
\cline { 2 - 10 } Bone & 1 & 2 & 3 & 4 & 5 & 6 & 7 & 8 & 9 & 10 & 11 & 12 & Total \\
\hline Frontal & - & + & - & - & + & + & - & + & + & + & + & + & 8 \\
Sphenoid & + & + & + & + & + & - & + & - & - & + & - & - & 7 \\
Optic foramen & + & + & + & + & + & - & - & - & - & + & - & - & 6 \\
Ethmoid & - & + & - & - & - & + & - & - & - & - & - & - & 2 \\
Maxilla & - & + & - & - & - & + & - & - & - & - & - & - & 2 \\
Occiput & - & - & - & + & - & - & - & - & - & + & - & - & 2 \\
Parietal & - & - & - & + & - & - & - & - & - & - & - & - & 1 \\
Petrous temporal & - & - & - & + & - & - & - & - & - & - & - & - & 1 \\
Pterygoid & - & + & - & - & - & - & - & - & - & - & - & - & 1 \\
Mandible & - & + & - & - & - & - & - & - & - & - & - & - & 1 \\
\hline
\end{tabular}

frequency of fibrous dysplasia of the craniofacial bones vary from 'rare' (5/764 cases of orbital tumours at the Mayo Clinic over 26 years)' to 'not uncommon' ( 144 cases of fibrous dysplasia of the skull). ${ }^{10}$

The aetiology remains obscure, but the condition is widely believed to be a congenital anomaly of bone forming mesenchyme. ${ }^{4}$ Hypotheses include misdifferentiation of mesenchymal tissue ${ }^{4}$ an 'arrest of bone maturation in the woven bone stage', ${ }^{11}$ and a 'disturbance of postnatal cancellous bone maintenance'. ${ }^{12}$ A traumatic aetiology has been suggested but not widely supported. ${ }^{13} 14$

Seventy per cent of cases involve only one bone/contiguous bones and are classed as monostotic, while $30 \%$ of cases are polyostotic. ${ }^{13}$ Skull involvement occurs in $10-27 \%$ of patients with monostotic, and in $50 \%$ of patients with polyostotic disease. ${ }^{15}$ Almost $100 \%$ of patients with extensive disease have skull involvement, ${ }^{15-18}$ but most patients with affected craniofacial bones have the monostotic form of the disease. ${ }^{192}$

Ocular complications have been classified into primary and secondary processes. ${ }^{21}$ Primary complications include involvement of the frontal bone with proptosis; the skull base with extraocular muscle palsies and trigeminal neuralgia; the optic canal with visual loss and optic atrophy; the sphenoid bones with chiasmal compression; and the maxillary bone with epiphora. Secondary complications comprise malignant change, ossifying fibroma formation, and development of a mucocele. Malignant transformation most commonly takes the form of sarcomatous change, occurring spontaneously in $0.5 \%$ of cases. $^{22}$

Other tumours known to develop in areas of fibrous dysplasia include cutaneous fibromyxoma ${ }^{23}$ and meningioma. ${ }^{24}$

\section{Materials and methods}

Twelve patients with orbital fibrous dysplasia underwent full neuro-ophthalmic assessment, 10 patients presenting for initial diagnosis and two for follow up after management elsewhere. All patients had a skull $x$ ray with serial films to assess progress. Five patients underwent computed tomography (CT) and two patients had magnetic resonance imaging (MRI).

Indications for surgical intervention comprised a deterioration in visual function, disfigurement, and intractable pain. Tissue was sent for histology from all surgically treated patients and a diagnostic biopsy alone was carried out in two patients.

Results

There were five male and seven female patients. Age at diagnosis ranged from 5 years to 45 years, 
Table 2 Fibrous dysplasia-symptoms

\begin{tabular}{ll}
\hline Symptom & Number of patients affected \\
\hline Visual upset & 4 \\
Proptosis & 5 \\
Craniofacial swelling & 5 \\
Headaches/periorbital pain & 5 \\
Epiphora & 1 \\
\hline
\end{tabular}

with an average age of 18 years. Eleven patients had idiopathic fibrous dysplasia, and one had Albright's syndrome. The skull bones affected are shown in Table 1. Most commonly involved were the frontal bone (eight patients) and the sphenoid bone (seven patients). Bilateral lesions occurred in three patients, one of whom had extensive skeletal involvement. Optic foraminal changes on plain $x$ ray were noted in six patients.

The mean follow up period was 8 years, ranging from 1 to 30 years.

\section{SYMPTOMS}

The presenting symptoms are shown in Table 2. Two patients were asymptomatic and diagnosed after routine skull $x$ ray following a trivial head injury, while the patient with Albright's syndrome presented with increased skin pigmentation and precocious puberty.

Table 3 Ophthalmic findings

\begin{tabular}{|c|c|c|c|c|c|c|}
\hline Patients & $\begin{array}{l}\text { Visual } \\
\text { acuity }\end{array}$ & Field loss & $\begin{array}{l}\text { Ocular motility } \\
\text { deficit }\end{array}$ & $\begin{array}{l}\text { Proptosis } \\
(\mathrm{mm})\end{array}$ & $\begin{array}{l}\text { Downward } \\
\text { displacement } \\
\text { (mm) }\end{array}$ & Disc \\
\hline 1 & $\mathrm{CF}$ & Centrocaecal scotoma & - & $3 \cdot 5$ & - & Swollen \\
\hline 2 & NPL & - & $10^{\circ}$ Exotropia ${ }^{\star}$ & $3 \cdot 0$ & - & Pale \\
\hline 3 & $6 / 18$ & Central scotoma & - & $2 \cdot 5$ & - & Normal \\
\hline 4 & $6 / 6$ & Slight constriction & - & - & - & Normal \\
\hline 5 & $6 / 6$ & - & - & $4 \cdot 0$ & - & Normal \\
\hline 6 & $6 / 6$ & Enlarged blind spot & Decreased elevation & $10 \cdot 0$ & $2 \cdot 0$ & Swollen \\
\hline 7 & $6 / 6$ & - & - & - & - & Normal \\
\hline 8 & $6 / 6$ & - & - & $2 \cdot 0$ & - & Normal \\
\hline 9 & $6 / 6$ & - & - & - & $2 \cdot 0$ & Normal \\
\hline 10 & $6 / 6$ & Temporal constriction & - & $2 \cdot 0$ & - & Normal \\
\hline 11 & $6 / 6$ & - & - & $3 \cdot 0$ & $2 \cdot 0$ & Normal \\
\hline 12 & $6 / 6$ & - & - & $11 \cdot 0$ & - & Pale \\
\hline
\end{tabular}

$\mathrm{CF}=$ counting fingers; $\mathrm{NPL}=$ no perception of light.

$\star$ This patient had a history of amblyopia.

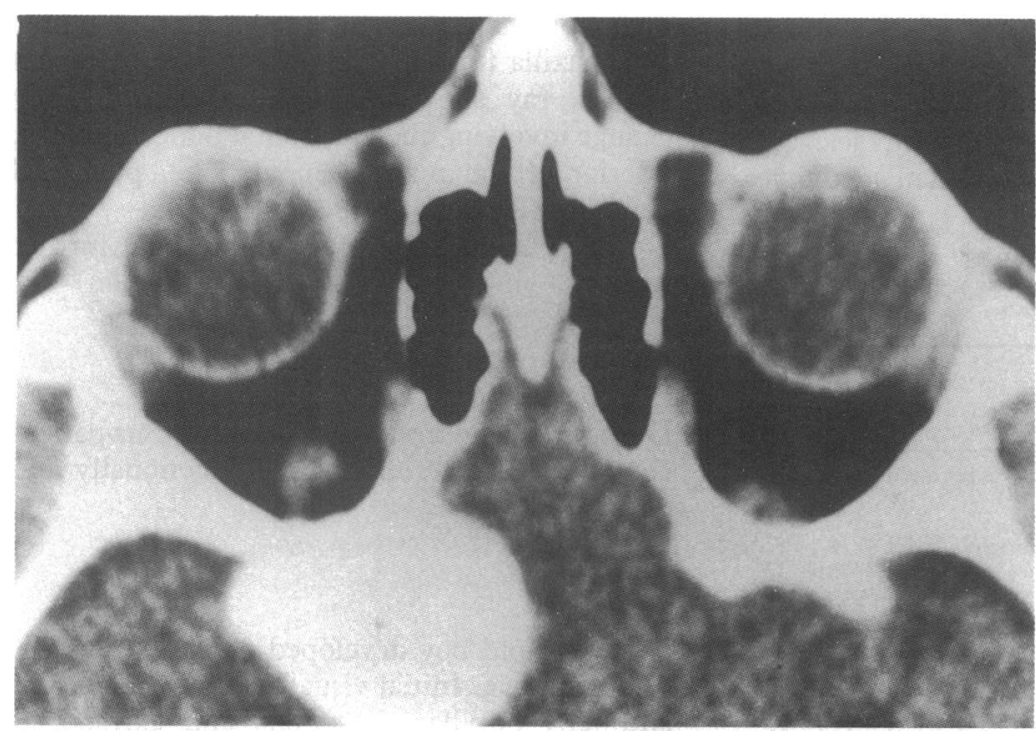

Figure 1 Computed tomogram of patient 1. Well defined mass at the apex of the right orbit, involving the greater wing of the sphenoid and surrounding the optic foramen.
Table 4 Effects of surgery

\begin{tabular}{cll}
\hline Patient & Preoperative & Postoperative \\
\hline 1 & $\begin{array}{l}\text { Visual acuity - counting fingers } \\
\text { Centrocaecal scotoma }\end{array}$ & $\begin{array}{l}\text { Visual acuity - 6/60 } \\
\text { Reduced }\end{array}$ \\
& 3.5 mm Proptosis & No proptosis \\
2 & No perception of light & No change \\
& 3 mm Proptosis & Fum Proptosis \\
5 & Constricted visual field & Full field \\
6 & Enlarged blind spot & Full field \\
10 & $10 \mathrm{~mm}$ Proptosis & Reduced \\
12 & Temporal field defect & $4 \mathrm{~mm}$ Proptosis \\
\hline
\end{tabular}

\section{OPHTHALMIC SIGNS}

The presenting ophthalmic signs are shown in Table 3. The commonest sign was proptosis in nine patients, accompanied by downward displacement of the globe in three patients. Loss of visual acuity in three patients ranged from $6 / 18$ to no perception of light.

\section{OTHER FINDINGS}

One patient developed conductive deafness secondary to secretory otitis media after blockage of the Eustachian tube.

\section{MANAGEMENT AND OUTCOME}

Six patients were managed conservatively, with a mean follow up period of 4.5 years (range 1 to 7 years). Four patients have shown radiological progression without significant change in visual function, while in two patients the disease appears to have arrested clinically and radiologically at the ages of 25 and 29 years.

Six patients underwent surgery. A conservative operation, comprising debulking and reshaping dysplastic bone, was carried out in four patients but all required further surgery, including a radical excision in two patients. Two patients had primary radical surgery.

The surgical and overall outcomes are shown in Tables 4 and 5 respectively. Following surgery, field defects improved in four patients and proptosis was reduced substantially in four patients. However, after conservative surgery all four patients developed recurrent disease, requiring further operations. In one patient the disease remains active after 30 years. No recurrence was encountered in two patients who had radical procedures after conservative operations, or in two patients who had primary radical surgery. The mean follow up period after radical surgery was 3.3 years (range 2 to 7 years)

Postoperative complications developed in three patients, in the form of transient vertical diplopia following frontal bone resection in two patients, and a postoperative subdural haematoma requiring surgical drainage in one patient. There were no long term sequelae.

\section{CASE ILLUSTRATIONS}

CASE 1

A 13-year-old boy complained of gradually deteriorating vision in the right eye for 6 months. Visual acuity in the right eye was reduced to counting fingers at 1 metre, with an afferent 


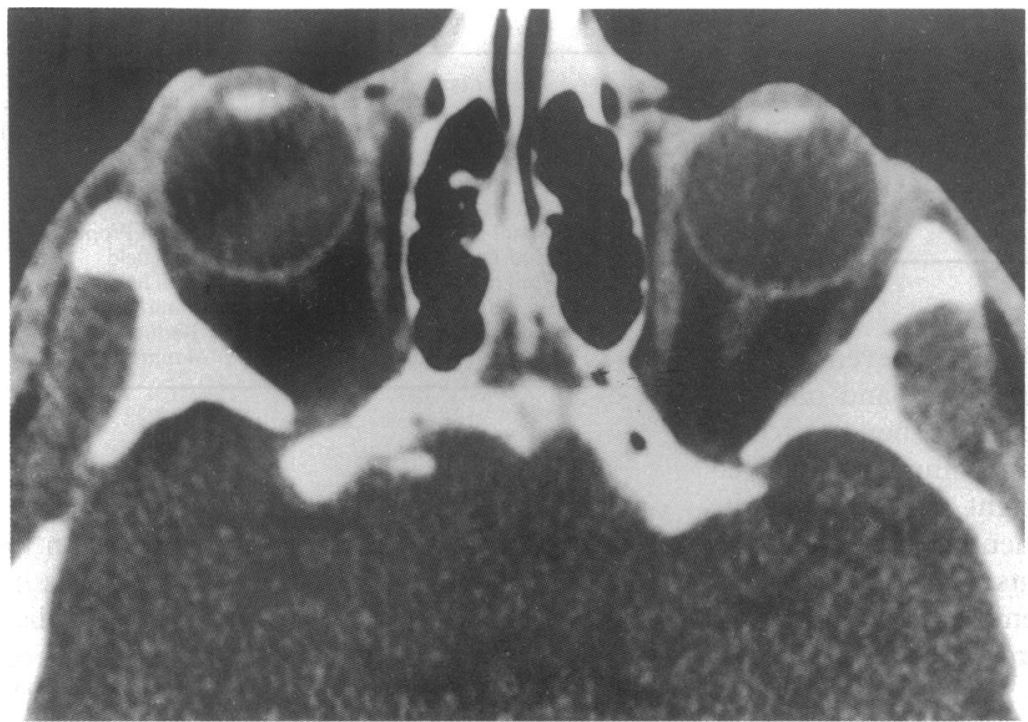

Figure 2 Computed tomogram of patient 1 following radical surgery, with slight residual soft tissue scarring at the orbital apex.

pupillary defect and papilloedema. The right visual field showed a dense centrocaecal scotoma and there was $3.5 \mathrm{~mm}$ of axial proptosis of the right eye. The left eye appeared healthy.

A CT scan revealed a well defined calcified mass involving the right medial sphenoid (greater wing) and anterior clinoid process, extending around the optic foramen (Fig 1).

A right frontotemporal craniotomy was performed and the dysplastic bone excised completely. Histology confirmed the diagnosis. Visual acuity improved to $6 / 60$ and the centrocaecal scotoma was reduced. The disc swelling and proptosis resolved.

A follow up CT scan showed complete removal of the lesion (Fig 2). This patient has been followed up for 3.5 years with no evidence of recurrence.

\section{Comment}

Radical excision resulted in an improvement in visual function and cosmetic appearance in this patient.

CASE 2

A 35-year-old female presented with facial asymmetry, at the age of 5 years. When aged 6 years

Table 5 Summary of management and outcome

\begin{tabular}{|c|c|c|c|c|c|c|}
\hline \multirow[b]{2}{*}{ Patient } & \multirow{2}{*}{$\begin{array}{l}\text { Age at } \\
\text { diagnosis } \\
\text { (years) }\end{array}$} & \multirow{2}{*}{$\begin{array}{l}\text { Duration of } \\
\text { active disease } \\
\text { (years) }\end{array}$} & \multicolumn{2}{|c|}{ Number of operations } & \multirow[b]{2}{*}{ Present condition } & \multirow{2}{*}{$\begin{array}{l}\text { Present } \\
\text { age } \\
\text { (years) }\end{array}$} \\
\hline & & & Conservative & Radical & & \\
\hline 1 & 13 & $1^{\star}$ & - & 1 & No evidence of fibrous dysplasia & 16 \\
\hline 2 & 5 & 30 & 5 & - & Active & 35 \\
\hline 3 & 32 & 2 & - & - & Active & 34 \\
\hline 4 & 12 & 5 & - & - & Active (Albright's) & 17 \\
\hline 5 & 13 & $12^{\star}$ & 1 & 1 & No evidence of fibrous dysplasia & 27 \\
\hline 6 & 10 & $2^{\star}$ & 2 & 1 & No evidence of fibrous dysplasia & 19 \\
\hline 7 & 19 & & - & - & Static. & 25 \\
\hline 8 & 23 & & - & - & Static & 29 \\
\hline 9 & 13 & 7 & - & - & Active & 20 \\
\hline 10 & 18 & 4 & 4 & - & Static & 33 \\
\hline 11 & 9 & 1 & - & - & Active & 10 \\
\hline 12 & 45 & $5^{\star}$ & - & 1 & No evidence of fibrous dysplasia & 51 \\
\hline
\end{tabular}

$\star$ Progress of disease halted by radical surgery.

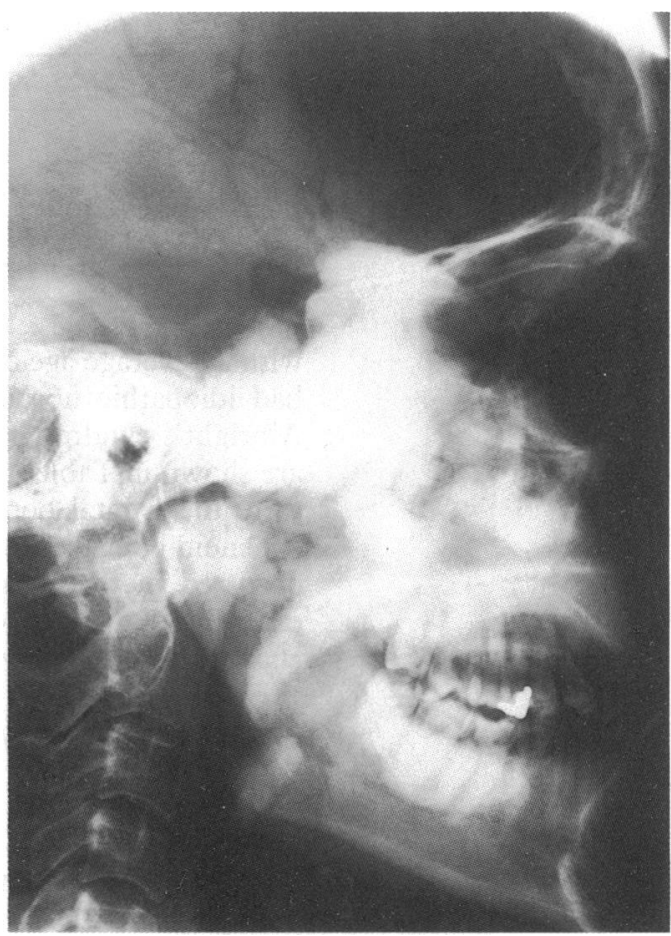

Figure 3 Skull $\mathrm{x}$ ray of patient 2 (lateral view), showing extensive involvement of the left side of the skull and facial bones.

decompressive surgery to the left maxilla for proptosis and upward displacement of the globe was carried out. Gradual deterioration in the visual acuity in the left eye occurred at the age of 10 years and the left orbit was decompressed. Visual acuity continued to decrease in the left eye until by the age of 14 years she had no perception of light owing to bony occlusion of the optic foramen. At the age of 21 she underwent further cosmetic surgery and when aged 24 years a further decompression of the left orbit was required to reduce proptosis. There was no apparent progression of the disease process during the next 8 years. At the age of 32 years she became pregnant for the first time and during the sixth month of her pregnancy noticed an increase in the size of her left mandible with lumps on her hard palate. Three years later she again became pregnant when the swellings of the left mandible and maxilla further increased in size. A recent skull $x$ ray showed extensive sclerotic bony change involving the left frontal bone, ethmoid, inferior orbital margin, nasal bone, pterygoid plate, maxilla, and mandible (Fig 3).

This patient is presently awaiting further surgery.

\section{Comment}

Despite five conservative procedures this patient continues to deteriorate both functionally and cosmetically.

\section{CASE 6}

A 10-year-old boy developed painless proptosis of the left eye. Initial visual acuity was $6 / 6$ right and left, pupillary reactions and extraocular movements were normal, optic discs were healthy, and visual fields full. A left frontal 


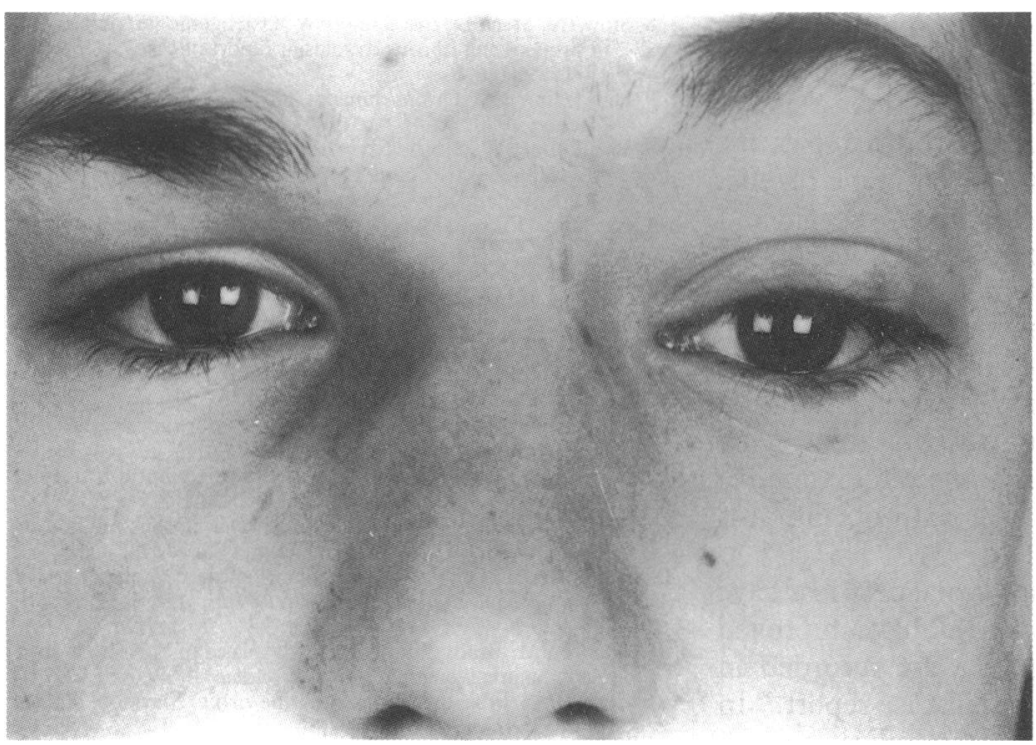

Figure 4 Patient 6. Note left proptosis and downward displacement of the globe, with frontalis overaction to compensate for left ptosis.

craniotomy was performed to debulk dysplastic bone for cosmetic reasons. At 2 years' follow up he complained of intermittent blurring of vision in the left eye. Visual acuity was $6 / 6$ right and left and the pupillary reactions were normal, but there was diminished elevation of the left eye, with vertical diplopia on upgaze. The left optic disc was swollen, left proptosis had increased to $10 \mathrm{~mm}$, and there was $2 \mathrm{~mm}$ downward displacement of the globe and a mild ptosis (Fig 4). The left visual field demonstrated an enlarged blind spot.

A CT scan showed a large oval lesion affecting the roof and medial wall of the left orbit with extension into the nasal cavity and displacement of the nasal septum. The optic canal was spared (Fig 5). A bifrontal craniotomy and block dissection was carried out. The medial wall and roof of the left orbit were excised with all dysplastic bone. Histology confirmed the diagnosis.

Postoperatively he made a good recovery.

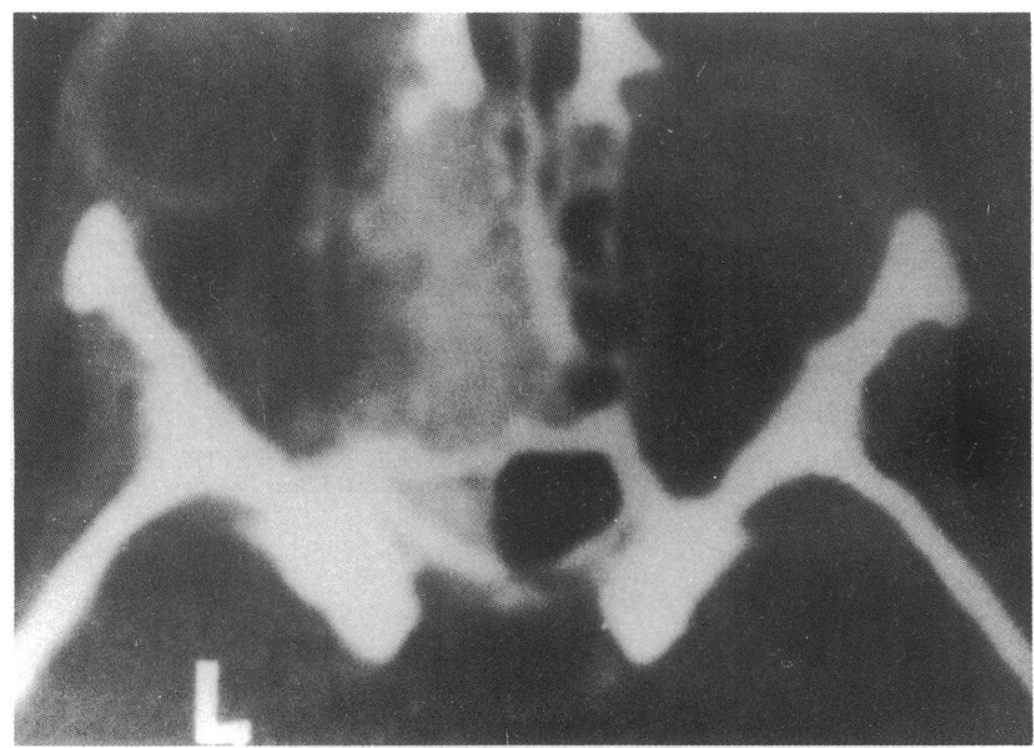

Figure 5 Computed tomogram of patient 6 showing oval lesion involving medial wall of the left orbit and extending into the nasal cavity. The nasal septum is displaced.
Visual acuity was maintained at $6 / 6$, ocular movements are full, the left optic disc swelling resolved, and the left proptosis was reduced to $4 \mathrm{~mm}$.

\section{Comment}

An initial conservative decompression was insufficient to control the functional and cosmetic effects of the disease process. Secondary radical excision has proved beneficial in this patient.

\section{Discussion}

In nine of our 12 patients the aetiology of the fibrous dysplasia was unknown (idiopathic), which is the common experience. ${ }^{1025}$ Two patients attributed their fibrous dysplasia to minor trauma, but it is likely that the association was purely incidental.

The frontal and sphenoid bones were affected most frequently, as in two other series, ${ }^{182627}$ and the optic foramen was involved in half our patients, a higher proportion than in two other series: 10 of 50 patients ${ }^{18}$ and five of 16 patients. ${ }^{28}$ This discrepancy may reflect the prolonged follow up of some of our patients.

Three patients demonstrated a decrease in visual acuity - more than in one series, ${ }^{28}$ where only two of 16 children had reduced visual acuity (although this may have been because of their young age), but less than in a further series of 10 patients, of whom eight suffered loss of visual acuity..$^{18}$ Visual field defects noted in five of our patients are not extensively documented in the literature, although a central scotoma was recorded in one patient ${ }^{29}$ and a bitemporal hemianopia in another. ${ }^{30}$

In common with other series, the most frequent ophthalmic sign was proptosis, affecting nine of our 12 patients. ${ }^{27} 281^{33}$ Although six patients had radiological evidence of optic foraminal involvement only two developed optic atrophy, and one papilloedema. It is recognised that compressive optic neuropathy does not always supervene, even with anatomical narrowing of the optic canal. ${ }^{27}$ Formerly, it was believed that the progression of fibrous dysplasia slowed down or stopped during adolescence. ${ }^{2}$ However, many exceptions to this premise are to be found, ${ }^{1634-36}$ including five patients in this series whose disease progressed after their teenage years. Only three patients demonstrated spontaneous arrest of their disease, and late reactivation occurred during pregnancy in one patient after 8 quiescent years. Reactivation or exacerbation of active disease is particularly liable to occur during gestation. ${ }^{37-39}$

Conservative surgery was previously regarded as the treatment of choice. ${ }^{354-42}$ However, the recurrence rate following conservative operations was significant at $25 \%$ in two series, ${ }^{25} 26$ and in 20 of 41 patients, 13 of 16 , and 13 of 15 patients in other series. ${ }^{21728}$ Radical surgery was avoided as it was thought that the disease may have a self-limiting course and there was a risk of complete excision causing more deformity and/ or functional loss than the disease itself. Following recent advances in anaesthesia and cranio- 
facial/plastic surgery, primary radical excision was carried out on five patients without recurrence after 9 years of follow up, while excision of all dysplastic bone in another three patients produced good functional and cosmetic results, although the follow up period was not specified..$^{43}$ The four patients who underwent radical operations in our series have demonstrated no recurrence of the disease during an average follow up period of 3.3 years, while all four patients who initially had conservative surgery required further operations. Two patients treated by conservative surgery have required four and five operations respectively and a sixth operation is proposed for the latter.

Four of five patients with visual field loss have improved postoperatively and all have improved cosmetically. Similar results were recorded in two other series ${ }^{2843}$ and a recent case report..$^{29}$ In accordance with the rate of complications for craniofacial surgery in the literature ${ }^{28434}$ only one of our patients developed a significant postoperative problem in the form of a subdural haematoma, but after surgical drainage there have been no long term sequelae. Attempts to arrest the disease process by radiotherapy in the past have been abandoned owing to an unacceptable $44 \%$ malignant transformation rate. ${ }^{22} 45$

\section{Conclusion}

Review of the histories of our 12 patients makes it apparent that fibrous dysplasia is not a disease confined to adolescence but may continue into adulthood and sometimes middle age. Some patients may never require surgery, but do require regular follow up for late progression, particularly during pregnancy. If surgical intervention is deemed necessary, an attempt should be made to excise all dysplastic bone and effect a cure. Progression of the disease after conservative surgery seems to be relatively common.

We thank Mr T A H Hide, consultant neurosurgeon, for referra of these cases for neuro-ophthalmic assessment, Mrs June of these cases for neuro-ophthalmic assessment, Mrs June Miss Rachel Gowing for careful preparation of this manuscript.
Mantions

1 Rootman J. Diseases of the orbit. Philadelphia: Lippincott, 1988: 356-9.

2 Nager GT, Kennedy DW, Kopstein E. Fibrous dysplasia: review of the disease and its manifestations in the temporal bone. Ann Otol Rhinol Laryngol 1982; 92 (suppl): 5.

3 Von Recklinghausen F. Die Fibrose oder deformierende Ostitis, die Osteomalacie und die oesteoplastische carcinose in ihren gegenseitigen Beziehungen. Festschrift Rudolf Virchow zum 13. Oktober, Berlin: 1891 .

4 Lichtenstein L, Jaffe HL. Polyostotic fibrous dysplasia. Arch Surg 1938; 36: 874-98.

5 Albright F, Butler MA, Hampton AO, Smith P. Syndrome characterized by osteitis fibrosa disseminata, areas of
pigmentation and endocrine dysfunction with precocious pigmentation and endocrine dysfunction with precocir

6 Wells C. Polyostotic fibrous dysplasia in a 7th century AngloSaxon. Br f Radiol 1963; 36: 925-6.

7 Gregg JB, Reed A. Monostotic fibrous dysplasia in the temporal bone: a late prehistoric occurrence. Am f Phys Anthropol 1980; 52: 587-93.
8 Slow IN, Stern D, Friedman EW. Osteogenic sarcoma arising in pre-existing fibrous dysplasia: report of case. $\mathcal{F}$ Oral Surg 1971; 29: 126-9.

9 Henderson JW. Orbital tumors. 2nd ed. New York: Brian C Decker, 1980: 70-4.

10 Van Tilburg W. Fibrous dysplasia. In: Vinken PJ, Bruyn GW eds. Handbook of clinical neurology. Vol 14. Amsterdam North Holland, 1972: 163-212.

11 Reed RJ. Fibrous dysplasia of bone. Arch Pathol 1963; 75: 480-95.

12 Aegerter EE, Kirkpatrick JA Jr. Orthopedic diseases. 3rd ed. Philadelphia: Saunders, 1968: 182-92.

13 Schlumberger HG. Fibrous dysplasia of single bones (monostotic fibrous dysplasia). Mil Surg 1947; 99: 504-27.

14 Reese AB. Fibrous dysplasia of bone. In: Tumours of the eye 3rd ed. London: Harper and Row, 1976: 326-7.

15 Windolz F. Cranial manifestations of fibrous dysplasia of bone. Am 7 Roentgen 1957; 58: 51-63.

16 Harris WH, Dudley HR Jr, Barry JR. The natural history of fibrous dysplasia. F Bone ft Surg 1962; 44A: 207-33.

17 Leeds N, Seaman WB. Fibrous dysplasia of the skull and its differential diagnosis. Radiology 1962; 78: 570-82.

18 Sassin JF, Rosenberg RN. Neurological complications of fibrous dysplasia of the skull. Arch Neurol (Paris) 1968; 18 363-9.

19 Calderon M, Brady HR. Fibrous dysplasia of bone with optic foramina involvement. Am $\mathcal{f}$ Ophthalmol 1969; 68: 513-5.

20 Moore RT. Fibrous dysplasia of the orbit. Surv Ophthalmo 1969; 13: 321-34.

21 Liakos GM, Walker CB, Carruth JAS. Ocular complications of craniofacial fibrous dysplasia. $\mathrm{Br} \mathcal{F}$ Ophthalmol 1979; 63: $611-6$.

22 Schwartz DT, Alpert $M$. The malignant transformation of fibrous dysplasia. Am $\mathcal{F}$ Med Sci 1964; 247: 1-20.

23 Lick RF, Viehweger F. A contribution to the diagnosis of fibrous dysplasia of the skeletal system. Fortschvitte auf dem Gebiete der Roentgenstratliten und der Nukkarmedezin 1962 97: 33-8.

24 Frankel J, Lanotti F, Powell M, Schon K. Meningioma - an unrecognised complication of fibrous dysplasia of the skull? f Neurol Neurosurg Psychiatry 1989; 52: 546-7.

25 Lichtenstein I, Jaffe HL. Fibrous dysplasia of bone. Arch Ophthalmol 1942; 33: 175-89.

26 Edgerton MJ, Persing JA, Jane JA. The surgical treatment of fibrous dysplasia. Ann Surg 1985; 202: 459-79.

27 Shields JA. Diagnosis and management of orbital tumours. Philadelphia: Saunders, 1989.

28 Moore AT, Buncic JR. Fibrous dysplasia of the orbit in childhood. Ophthalmology 1985; 92: 12-20.

29 Weisman JS, Major US, Helper RS, Vintners V. Reversible visual loss caused by fibrous dysplasia. Am $\mathcal{F}$ Ophthalmo 1990; 110: 244-9.

30 Weyand RD, Craig WM, Rucker CW. Unusual lesion involving the chiasm. Proc Mayo Clinic 1952; 27: 505-15.

31 Mortada A. Fibrous dysplasia of the orbital bones. Brf Ophthalmol 1961; 45: 737-40.

32 Schonder A. Fibrous dysplasia of the bone with proptosis. Am $\mathcal{F}$ Dis Child 1977; 131: 678-9.

33 Friot JM, Bleicher B, Galoisy C, Bretagne MC, Chobaut JC, Wayoff $M$. Four cases of exophthalmos of unusual nasosinus origin. Revue d'oto-neuro-ophtalmologie 1978; 50: $141-9$.

34 Frazer AK, Hannah RH, Buxton PH. Fibrous dysplasia of the ethmoid presenting with proptosis. Br $\mathcal{F}$ Surg 1969; 56 $300-7$

35 Ramsey HE, Strong EW, Frazell EL. Fibrous dysplasia of the craniofacial bones. Am F Surg 1968; 116: 542-7.

36 Chen YR, Fairholm D. Fronto-orbito-sphenoidal fibrous dysplasia. Ann Plast Surg 1985; 15: 190-203.

37 Hunter D, Turnbull HL. Hyperparathyroidism; generalised osteitis fibrosa. Brf S Surg 1931; 32: 203-84.

38 Dockerty MD, Ghormley BK, Kennedy RLJ, Pugh DG Albright's syndrome. Arch Intern Med 1945; 75: 357-75.

39 Bonduelle M, Claisse R. Dysplasie Fibreuse des os et Syndrome d'Albright leur place nosologique. Sem Hôp Pari 1948; 24: 514-21

40 Gass JDM. Orbital and ocular involvement in fibrous dysplasia. South Med F 1965; 58: 324-9.

41 Rychener RO, Murfey F. Periorbital fibrous dysplasia. Tran Am Ophthalmol Soc 1955; 53: 155-74.

42 Feiring W, Feiring EH, Davidoff ML. Fibrous dysplasia of the skull. F Neurosurg 1951; 8: 377-97.

43 Munro IR, Chen YR. Radical treatment for fronto-orbital fibrous dysplasia: the chain-link fence. Plast Reconstr Surg 1981; 67: 719-30.

44 Whitaker LA, Munro IR, Salyer KE, Jackson IT, Ortiz Monasterio F, Marchac D. Problems and complications in 793 craniofacial operations. Reconstr Surg 1979; 64 198-203.

45 Huvos AG, Higinbotham NL, Miller TR. Bone sarcomas arising in fibrous dysplasia. F Bone foint Surg $(A m)$ 1972; 54 1047-56. 